\title{
Processing Map for Hot Working of Alpha-Zirconium
}

\author{
J.K. CHAKRAVARTTY, Y.V.R.K. PRASAD, and M.K. ASUNDI
}

The hot deformation characteristics of alpha-zirconium in the temperature range of $650{ }^{\circ} \mathrm{C}$ to $850{ }^{\circ} \mathrm{C}$ and in the strain-rate range of $10^{-3}$ to $10^{2} \mathrm{~s}^{-1}$ are studied with the help of a power dissipation map developed on the basis of the Dynamic Materials Model ${ }^{[7,8,9]}$ The processing map describes the variation of the efficiency of power dissipation $(\eta=2 m / m+1)$ calculated on the basis of the strain-rate sensitivity parameter $(m)$, which partitions power dissipation between thermal and microstructural means. The processing map reveals a domain of dynamic recrystallization in the range of $730^{\circ} \mathrm{C}$ to $850^{\circ} \mathrm{C}$ and $10^{-2}$ to $1 \mathrm{~s}^{-1}$, with its peak efficiency of 40 pct at $800{ }^{\circ} \mathrm{C}$ and $0.1 \mathrm{~s}^{-1}$, which may be considered as optimum hot-working parameters. The characteristics of dynamic recrystallization are similar to those of static recrystallization regarding the sigmoidal variation of grain size (or hardness) with temperature, although the dynamic recrystallization temperature is much higher. When deformed at $650{ }^{\circ} \mathrm{C}$ and $10^{-3} \mathrm{~s}^{-1}$, texture-induced dynamic recovery occurred, while at strain rates higher than $1 \mathrm{~s}^{-1}$, alpha-zirconium exhibits microstructural instabilities in the form of localized shear bands which are to be avoided in processing.

\section{INTRODUCTION}

THE hot deformation characteristics of alpha-zirconium have been studied earlier ${ }^{[1,2]}$ and analyzed using the kinetic rate equation. The apparent activation energy estimated from this analysis was found to be close to that for self-diffusion in this material, and the mechanism of hot deformation was suggested to be that involving dynamic recovery ${ }^{[2]}$ in view of the high stacking fault energy of zirconium. ${ }^{[3,4]}$ The data used for the above analysis were up to a strain rate of $3 \times 10^{-1} \mathrm{~s}^{-1}$, which is rather low when compared with that encountered in commercial metalworking operations. Further in the above kinetic analysis, an Arrhenius-type rate equation is used along with a power law relation between flow stress and strain rate. It is generally assumed that the stress exponent is independent of strain rate and temperature, and the experimental data obtained over a wide range showed that this assumption is not strictly valid..$^{[5,6]}$ The aim of this investigation is to use the recently developed Dynamic Materials Model ${ }^{[7,8,9]}$ for analyzing the constitutive behavior of alpha-zirconium at high temperature in a wide range of strain rates. According to this approach, the power dissipation characteristics of the material through microstructural changes are evaluated with the help of strain-rate sensitivity and mapped as a function of temperature and strain rate. These processing maps are interpreted in terms of specific microstructural mechanisms that dominate in a given temperature-strain-rate regime. Using this approach, it is possible not only to optimize hot workability but also to delineate regimes of flow instability ${ }^{[9,10]}$ which should strictly be avoided in processing.

J.K. CHAKRAVARTTY, Scientific Officer, is with the Metallurgy Division, Bhabha Atomic Research Centre, Bombay 400 085, India. Y.V.R.K. PRASAD, Professor, is with the Department of Metallurgy, Indian Institute of Science, Bangalore 560 012, India. M.K. ASUNDI, formerly Divisional Head, Physical Metallurgy Division, Bhabha Atomic Research Centre, is an Emeritus Scientist with the Naval Chemical and Metallurgical Laboratory, Tiger Gates, Bombay-400 023, India.

Manuscript submitted March 14, 1990.

\section{EXPERIMENTAL}

The material used in the present study was commercially pure reactor-grade zirconium (containing approximately $1000 \mathrm{ppm}$ of oxygen) obtained in the form of extruded and cold drawn rods of $15-\mathrm{mm}$ diameter. $\mathrm{Cy}-$ lindrical compression specimens $(10 \mathrm{~mm}$ in diameter and $15 \mathrm{~mm}$ height) were machined from the as-received rods. The machined samples were sealed in silica tubes under helium and beta-quenched from $1030{ }^{\circ} \mathrm{C}$ after soaking for 30 minutes. Samples were deformed at constant true strain rates of $0.001,0.01,0.1,1,10$, and $100 \mathrm{~s}^{-1}$ over a temperature range of $6500^{\circ} \mathrm{C}$ to $850{ }^{\circ} \mathrm{C}$ at $50 \mathrm{deg}$ intervals to a true strain of about 70 pct. The compression testing was done on a computer-controlled servohydraulic test system (DARTEC, Stourbridge, West Midlands, United Kingdom) which has the facility for an exponential decay of actuator speed so that constant true strain rates may be obtained. The lubrication was done with molten glass and was made effective by engraving concentric grooves on both faces of the specimen. The adiabatic temperature rise during compression was measured by embedding a thermocouple into the specimen. The temperature rise was as high as $80^{\circ} \mathrm{C}$ during deformation at highest strain rate $\left(100 \mathrm{~s}^{-1}\right)$ and lowest test temperature $\left(650^{\circ} \mathrm{C}\right)$. True stress-true plastic strain curves were evaluated from the load-stroke data using standard equations. Some selected specimens were sectioned along the compression axis, and the microstructure was examined optically.

\section{RESULTS}

Typical true stress-true plastic strain of alpha-zirconium recorded at $800{ }^{\circ} \mathrm{C}$ and different strain rates in compression are shown in Figure 1. Except at strain rates of $10 \mathrm{~s}^{-1}$ and above, the curves are observed to be nearly steady state. The curves at $0.1 \mathrm{~s}^{-1}$ at all temperatures were found to be nearly horizontal. The flow stress values corrected for adiabatic temperature rise at various temperatures, strain rates, and strains are shown in Table I. The strain-rate sensitivity $(m)$ is evaluated by 


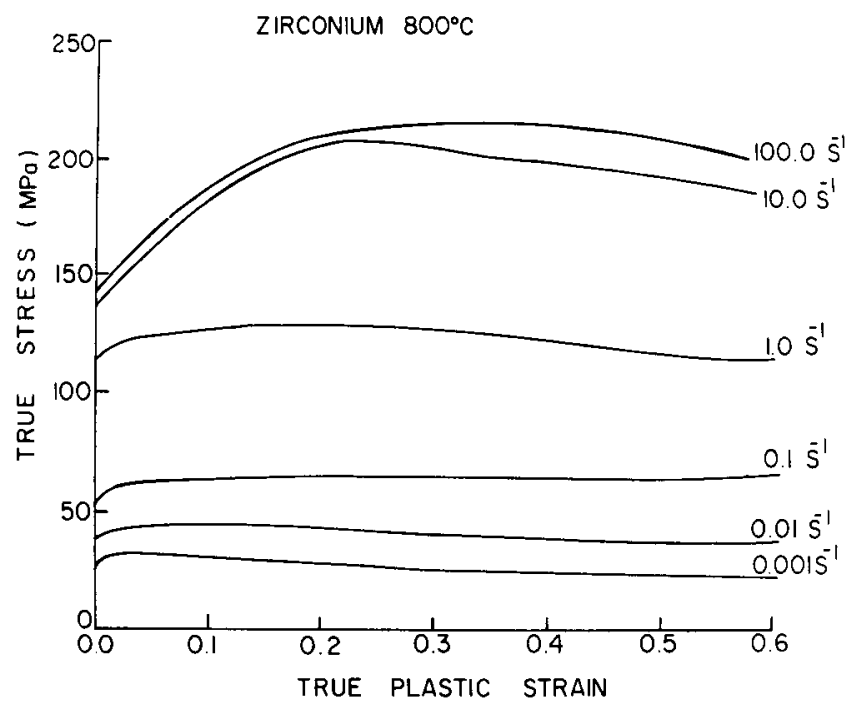

Fig. 1-True stress-true plastic strain plots of alpha-zirconium for various strain rates at $800^{\circ} \mathrm{C}$.

fitting a cubic spline to the log flow stress $v s \log$ strainrate data at each temperature and strain and finding its slope as a function of strain rate. The efficiency of power dissipation $^{[7]}$

$$
\eta=2 m /(m+1)
$$

is calculated and plotted as a three-dimensional (3-D) variation, with temperature and strain rate at a constant strain. The 3-D power dissipation map for alpha-zirconium for a strain of 0.2 is shown in Figure 2(a). The corresponding contour map representing isoefficiency contours on the strain-rate-temperature surface is shown in Figure 2(b). The map for a strain of 0.5 is shown in Figure 3 , and maps at $0.1,0.3$, and 0.4 are identical to this. A comparison of Figures 2(b) and 3 clearly shows that the effect of strain is negligible.

The continuum criterion for the occurrence of microstructural instabilities, developed by Kumar ${ }^{[10]}$ on the basis of Ziegler's ${ }^{[11]}$ principle of maximum rate of entropy production, is examined on the basis of the above data (Table I). It has been shown that instabilities in microstructure will occur in processing if

$$
\xi(\dot{\varepsilon})=\delta \ln [m /(m+1)] /(\delta \ln \dot{\varepsilon})+m<0
$$

The variation of the instability parameter $\xi(\dot{\varepsilon})$ with temperature and strain rate is shown in Figure 4 for a strain of 0.2 . The instability map is identical to this at other strains. Microstructural instability is predicted to occur within the area bounded by the contour $G$, where $\xi(\dot{\varepsilon})$ is negative. By superimposing this instability map on the processing map (Figure $2(\mathrm{~b})$ ), the area of instability gets delineated. Microstructural instability will occur at

Table I. Corrected Flow Stress (in MPa) Values at Various

Strains, Strain Rates, and Temperatures for Alpha-Zirconium

\begin{tabular}{ccccccc}
\hline & Strain Rate & \multicolumn{5}{c}{ Temperature, ${ }^{\circ} \mathrm{C}$} \\
\cline { 2 - 6 }$\left(\mathrm{s}^{-1}\right)$ & 650 & 700 & 750 & 800 & 850 \\
\hline 0.1 & 0.001 & 66.2 & 58.8 & 32.6 & 30.1 & 23.8 \\
& 0.01 & 97.4 & 82.0 & 56.9 & 43.5 & 38.5 \\
& 0.1 & 170 & 125 & 78 & 63 & 50 \\
& 1 & 150 & 145 & 155 & 132 & 95 \\
& 10 & 171 & 168 & 160 & 160 & 145 \\
0.2 & 100 & 210 & 185 & 146 & 165 & 150 \\
& 0.001 & 68.6 & 56.8 & 31.2 & 27.4 & 22.4 \\
& 0.01 & 102 & 76.2 & 56 & 41.7 & 38.3 \\
& 0.1 & 176 & 125 & 80 & 60 & 51 \\
& 1 & 184 & 177 & 169 & 128 & 95 \\
0.3 & 10 & 205 & 200 & 184 & 185 & 160 \\
& 100 & 275 & 230 & 185 & 200 & 168 \\
& 0.001 & 68 & 54 & 29.6 & 25 & 21 \\
& 0.01 & 103 & 75.5 & 54.1 & 39.2 & 36.4 \\
& 0.1 & 190 & 125 & 82 & 60 & 45 \\
& 1 & 200 & 190 & 178 & 135 & 90 \\
& 10 & 255 & 225 & 200 & 205 & 150 \\
& 100 & 300 & 250 & 210 & 210 & 180 \\
& 0.001 & 69 & 51 & 28 & 23 & 20 \\
& 0.01 & 105 & 75 & 53 & 38 & 35 \\
& 0.1 & 190 & 122 & 80 & 60 & 50 \\
& 1 & 205 & 191 & 175 & 131 & 90 \\
& 10 & 261 & 217 & 200 & 200 & 150 \\
& 100 & 320 & 260 & 219 & 220 & 180 \\
& 0.5 & 69.5 & 49.6 & 26.6 & 22 & 18.8 \\
& 0.001 & 104 & 72.7 & 50.2 & 37 & 33 \\
& 0.01 & 189 & 127 & 77.7 & 63.9 & 48 \\
& 10 & 221 & 194 & 170 & 128 & 88 \\
& 100 & 337 & 254 & 204 & 194 & 149 \\
& 1 & & & 210 & 176 \\
\hline
\end{tabular}




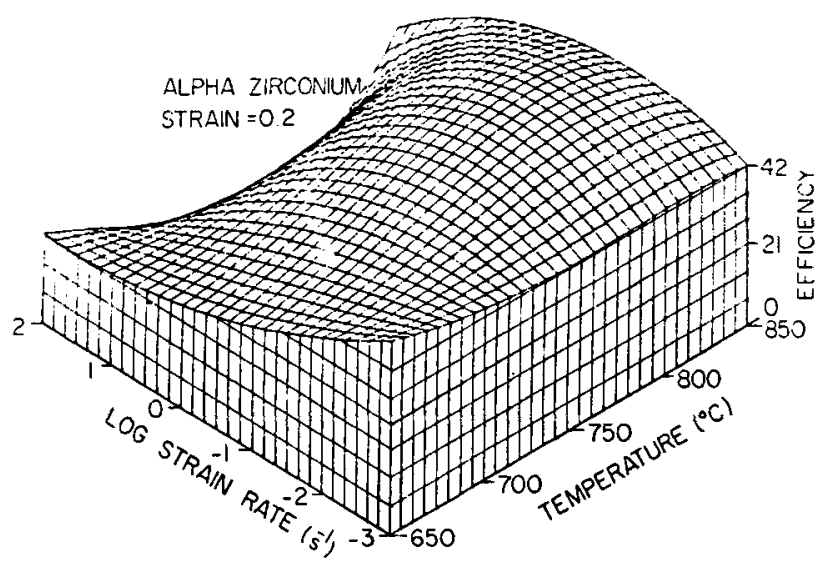

(a)

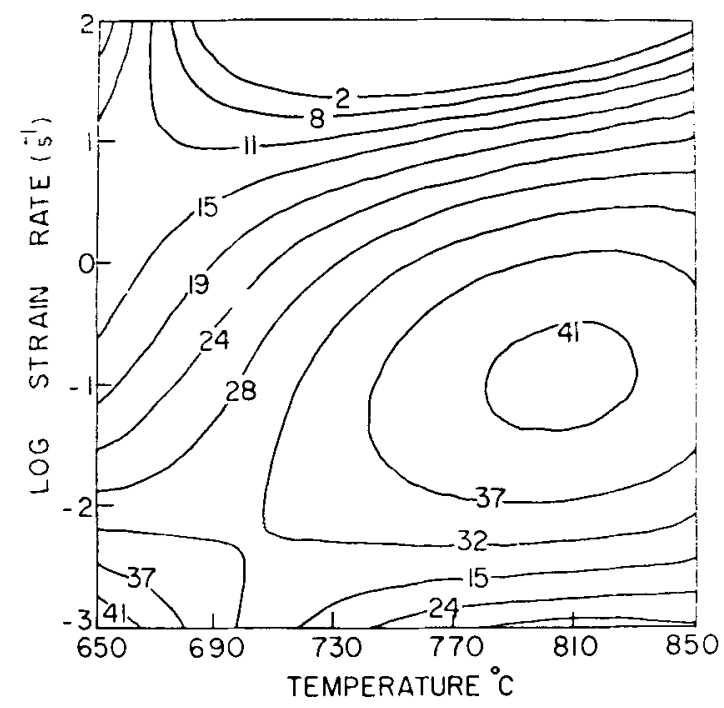

(b)

Fig. 2-Processing map for alpha-zirconium for a strain on 0.2: (a) variation of the efficiency of power dissipation with temperature and strain rate and $(b)$ contour map showing isoefficiency contours on strain-rate and temperature surface.

temperatures higher than $670{ }^{\circ} \mathrm{C}$ and at strain rates higher than $1 \mathrm{~s}^{-1}$.

\section{DISCUSSION}

\section{A. Interpretation of Power Dissipation Maps}

The basis for the interpretation of the power dissipation maps is the Dynamic Materials Model developed by Prasad et al.$^{[7]}$ and reviewed recently by Gegel ${ }^{[8]}$ This model follows a systems approach and is based on the fundamental principles of continuum mechanics of large plastic flow. ${ }^{[1]}$ The workpiece is considered as a nonlinear dissipator of power, and its constitutive behavior describes the manner in which the energy is converted at any instant into a form, thermal or microstructural, which is irreversible.

Following systems terminology, ${ }^{[12]}$ the instantaneous power dissipated may be considered to consist of two complimentary parts: $G$-content, representing the tem-

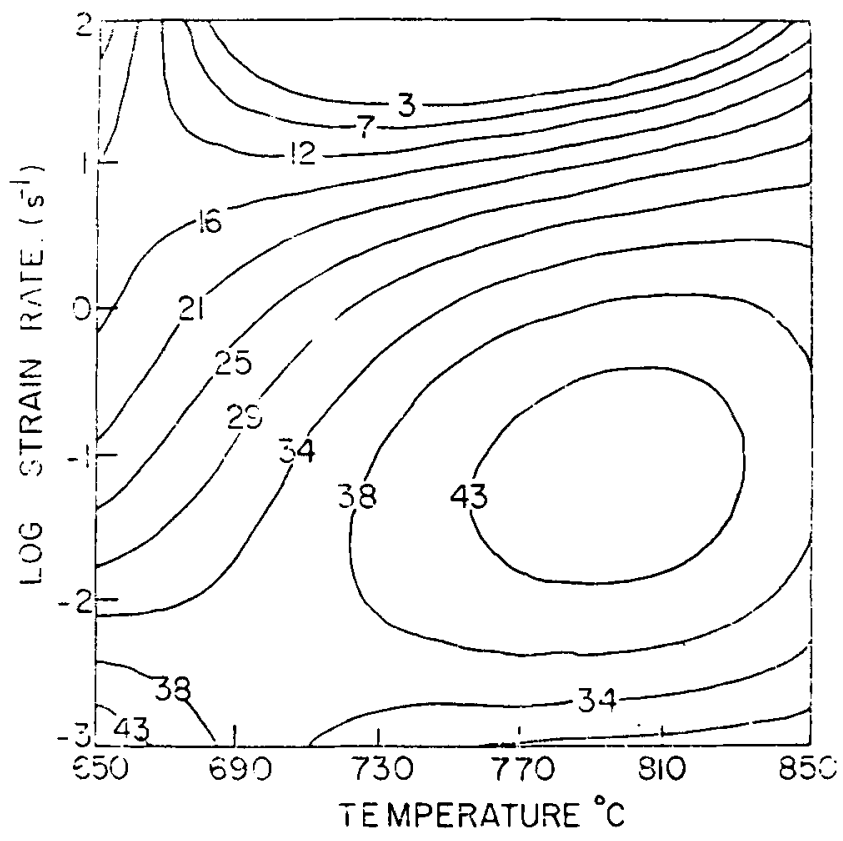

Fig. 3-Processing map of alpha-zirconium for a strain of 0.5 (isoefficiency contours on temperature-strain-rate surface).

perature rise, and $J$-content, representing the dissipation through metallurgical processes. The factor that partitions power between $J$ and $G$ is strain-rate sensitivity $(m)$ of flow stress, and the $J$ co-content is given by

$$
J=\sigma \dot{\varepsilon} m /(m+1)
$$

where $\sigma=$ flow stress and $\dot{\varepsilon}=$ strain rate. For an ideal linear dissipator, $m=1$ and $J=J_{\max }=\sigma \dot{\varepsilon} / 2$. The efficiency of power dissipation of a nonlinear dissipator may be expressed as a dimensionless parameter:

$$
\eta=J / J_{\max }=2 m /(m+1)
$$

The power dissipation characteristic of the workpiece

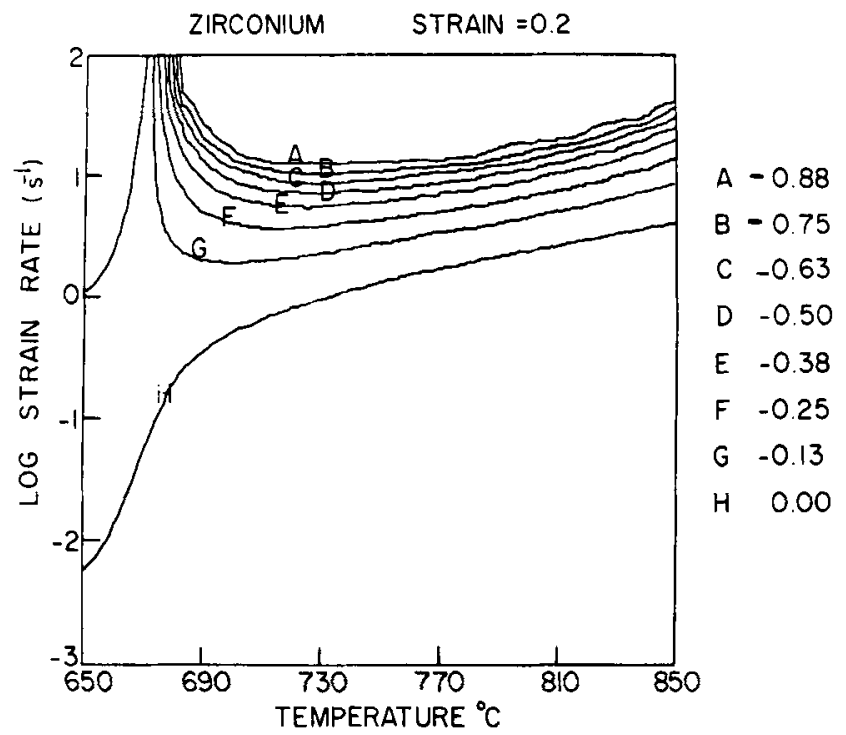

Fig. 4-Variation of instability parameter $\xi(\dot{\varepsilon})$ with temperature and strain rate. Instability is predicted when $\xi(\dot{\varepsilon})$ is negative. 
material through microstructural changes in processing is represented through the efficiency variations.

As the system is irreversible, the dissipated power is directly related to the rate of entropy production, which is always positive ${ }^{[11]}$ In systems which have a high rate of entropy production, the concepts of self-organization of chaotic systems proposed by Prigogine ${ }^{[13]}$ are applicable, and the power dissipation maps may be interpreted to represent the rate of entropy production. The maps can then be taken to represent domains of local order (concentric isoefficiency contours) corresponding to specific dissipative mechanisms (structures) separated by bifurcations which are probability related. The domains are deterministic, and dissipative structures characterize the domains.

The power dissipation maps are continuum maps, and the domains will have to be interpreted in terms of specific atomistic processes that cause the dissipation. This can be done with the help of "Raj maps." ${ }^{[14]}$ In hot deformation, there are "safe" and "damage" processes that occur at different temperature-strain-rate combinations. The safe mechanisms are dynamic recovery (low temperature and low strain rates) and dynamic recrystallization (high temperatures and intermediate strain rates). Microstructural damage due to wedge cracking will occur at lower strain rates and higher temperatures, while void formation at hard particles dominates at high strain rates and lower temperatures. The damage processes are very efficient in dissipating power through the generation of new surfaces, while the "safe" processes are less efficient, since power dissipation occurs by annihilation of dislocations or their groups. Out of the two safe processes, dynamic recrystallization has a higher efficiency than dynamic recovery and is preferred for hot working.

On the basis of Raj maps, ${ }^{[14]}$ the domain occurring at $800{ }^{\circ} \mathrm{C}$ and $10^{-1} \mathrm{~s}^{-1}$ in the power dissipation maps (Figure 2(b)) represents the domain of dynamic recrystallization of zirconium. For this domain, the range of temperature is from about $730{ }^{\circ} \mathrm{C}$ to about $870^{\circ} \mathrm{C}$. The strain-rate range is from about $5 \times 10^{-2}$ to $2 \mathrm{~s}^{-1}$. The efficiency of power dissipation varies from 34 pet to a peak of about 42 pct. The microstructure of the specimen quenched from $800^{\circ} \mathrm{C}$ after deformation to a true strain of 0.7 at $0.1 \mathrm{~s}^{-1}$ is shown in Figure 5(a) and compared with the microstructure of the starting material (Figure 5(b)) which had transformed beta plates resulting from beta-quenching. The dynamic recrystallized microstructure showed features of new grains originating from the platelet interfaces which are corrugated. When the specimen is furnace cooled after deformation, the microstructure showed nearly equiaxed grain structure (Figure 5(c)). The variation of average grain diameter produced by dynamic recrystallization as a function of temperature within the dynamic recrystallization domain is shown in Figure 6. The grain size increased sigmoidally with temperature, and the 50 pct grain size variation occurred at about $800{ }^{\circ} \mathrm{C}$, which matches with the temperature for the peak efficiency at $0.1 \mathrm{~s}^{-1}$. Thus, this temperature may be designated as dynamic recrystallization temperature. The tensile ductility variation with temperature from the investigations of Garde is also shown in Figure $6,{ }^{[15]}$ and the temperature for peak ductility matches approximately with the dynamic recrystalliza- tion temperature. The small shift (25 deg) in the temperature of the peak ductility may be attributed to the slower strain rate employed by Garde. ${ }^{[15]}$ The variation of average grain diameter with strain rate within the domain at $800^{\circ} \mathrm{C}$ is shown in Figure 7 , which shows grain refinement with increasing strain rate.

In Figure 8, the static recrystallization behavior of alphazirconium is shown in terms of the variation of hardness with temperature reported by Gray, as cited by Douglass. ${ }^{[16]}$ The static recrystallization temperature is about $600^{\circ} \mathrm{C}$. It is seen clearly from Figures 6(a) and 8 that the behavior of static and dynamic recrystallization is strikingly similar, although the dynamic recrystallization temperature is much higher $\left(800^{\circ} \mathrm{C}\right)$ in comparison with the static recrystallization temperature $\left(\simeq 600^{\circ} \mathrm{C}\right)$. All these results confirm that the domain at $800{ }^{\circ} \mathrm{C}$ and $0.1 \mathrm{~s}^{-1}$ represents the process of dynamic recrystallization.

\section{B. Model for Dynamic Recrystallization}

A simple model of dynamic recrystallization is presented here to account for the above observations. Unlike in static recrystallization, where a fixed quantity of stored energy has to be released by dissipative processes involving nucleation and growth, the energy is continuously input into the material at a given rate and dissipated through softening processes in dynamic recrystallization. The energy input is through the generation of interfaces involving dislocations and their recovery, while the energy of dissipation occurs by migration of interfaces. Thus, the rate of generation of interfaces $v s$ the rate of migration will decide the shape of the flow stress-plastic strain-rate curves and the characteristic of power dissipation. For example, if the rate of interface formation is equal to the rate of their migration, steady-state flow curves will result, and peak in the efficiency of power dissipation will occur in the map.

Approximate calculation of the order of magnitude of these rates may be made as follows: the rate of interface formation, $R_{F}$, depends on the rate of dislocation generation and probability of their recovery

$$
R_{F}=(\dot{\varepsilon} / \mathbf{b} l) \exp \left[-\alpha \mu \mathbf{b}^{2} d /(\mathrm{k} T)\right]
$$

where $\dot{\varepsilon}=$ strain rate, $\mathbf{b}=$ Burgers Vector, $l=$ link length of dislocations, $\alpha=$ constant, $\mu=$ shear modulus, $d=$ stacking fault width, $\mathrm{k}=$ Boltzmann's constant, and $T=$ absolute temperature. Since zirconium has relatively high stacking fault energy, $d=3 \mathrm{~b},,^{11,4]}$ and at $\dot{\varepsilon}=0.1 \mathrm{~s}^{-1}$ and $l=10^{-6} \mathrm{~m}, R_{F} \simeq 10^{10} \mathrm{~m}^{-2} \mathrm{~s}^{-1}$ (taking $\alpha=1 / 15$ and $\mu=2.1 \times 10^{10} \mathrm{~J} / \mathrm{m}^{3}$ ). This is the length of interface produced per unit volume per second.

The rate of interface migration per unit area of the interface is given by

$$
R_{M}=D \Gamma /(\mathbf{k} T \mathbf{b})
$$

where $D=D_{0} \exp \left[-Q_{S D} / \mathrm{R} T\right]$ and $\Gamma=$ grain-boundary energy. At $800^{\circ} \mathrm{C}, D_{0}=6 \times 10^{-6} \mathrm{~m}^{2} / \mathrm{s}, Q_{\mathrm{SD}}=218 \mathrm{~kJ} /$ $\mathrm{mol}$, and $\Gamma=780 \mathrm{~mJ} / \mathrm{m}^{2}$ calculated from solid surface free energy. ${ }^{[17,18]}$ The value of $R_{M}$ is calculated to be $2.4 \times 10^{13} \mathrm{~m}^{-1} \mathrm{~s}^{-1}$. For comparing $R_{M}$ with $R_{F}, R_{F}$ has to be converted into a value per unit area of the interface. Assuming that the total interface length is arranged in 

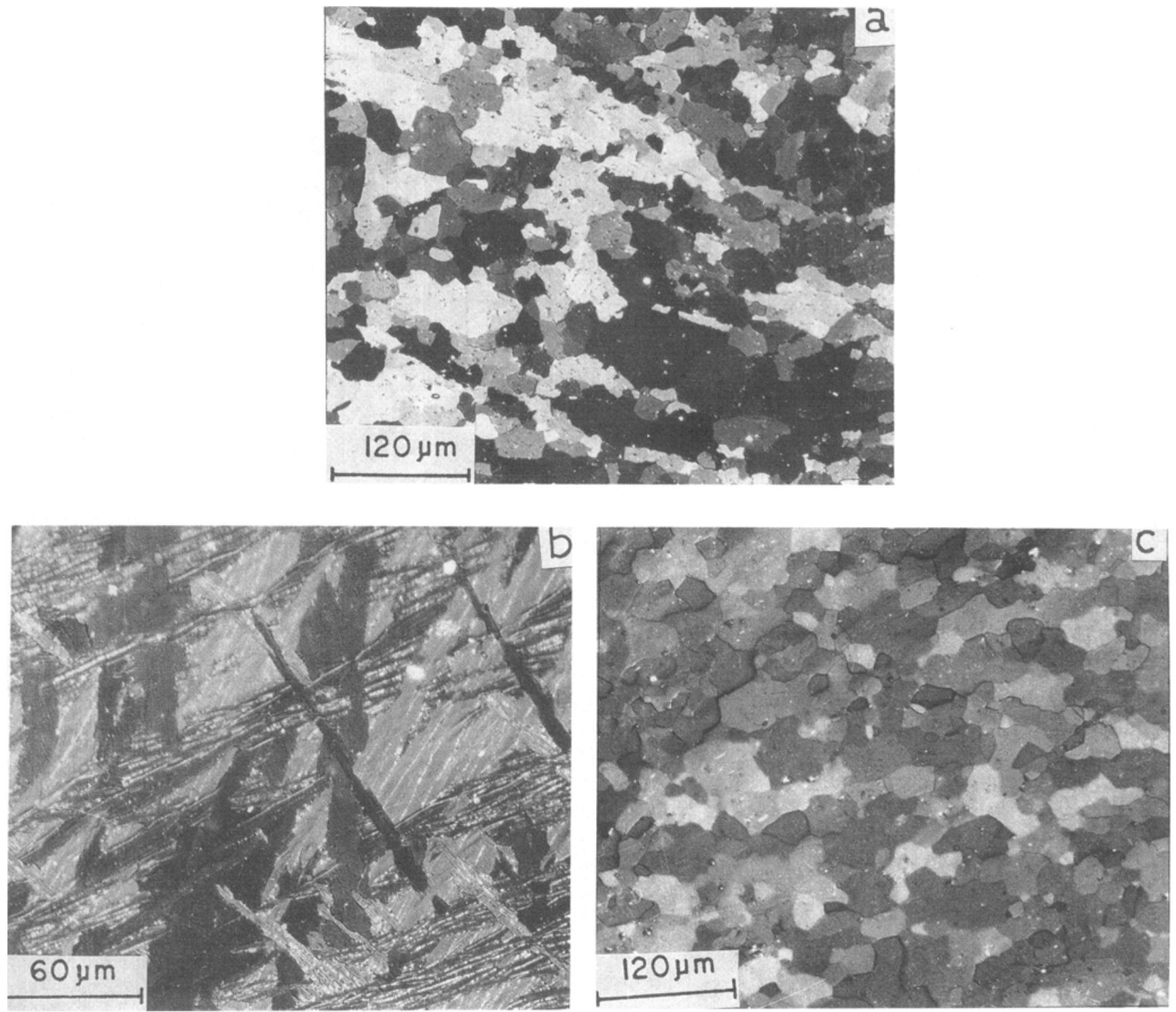

Fig. 5-Optical micrographs of (a) dynamically recrystallized alpha-zirconium at $800^{\circ} \mathrm{C}$ and $0.1 \mathrm{~s}^{-1}$ to a strain of $0.7,(b)$ starting microstructure showing beta-quenched alpha-zirconium, and $(c)$ a completely recrystallized structure of deformed alpha-zirconium at $800{ }^{\circ} \mathrm{C}$ and furnace cooled.

the form of a cube of side $\sqrt[3]{R_{F}}$, the value of the rate of formation per unit area will be $6 \times 10^{13} \mathrm{~m}^{-1} \mathrm{~s}^{-1}$. Thus, at $800^{\circ} \mathrm{C}$, the rate of formation of interfaces is of the same order as that of migration and, therefore, results in steady-state flow curve and peak efficiency of dissipation. At lower temperatures, the rate of migration is lower (at constant $\dot{\varepsilon}$ ), and at high strain rates, the rate of formation is higher (at constant temperature). These conditions result in finer dynamic recrystallized grain size (Figures 6(a) and 7).

The map shows that a separate domain occurs at temperatures lower than about $700{ }^{\circ} \mathrm{C}$ and at strain rates lower than $10^{-2} \mathrm{~s}^{-1}$ (lower left-hand corner of the map of Figure 2(b)). The efficiency in this domain is slightly higher $(42 \mathrm{pct})$ than that of dynamic recrystallization and increases with decrease in temperature and strain rate. The microstructure recorded on the specimen deformed at $650{ }^{\circ} \mathrm{C}$ and $10^{-3} \mathrm{~s}^{-1}$ is shown in Figure 9 both as optical and transmission electron micrographs. The microstructure is typical of dynamically recovered material. In this temperature range, dynamic recovery process was also identified by Abson and Jonas. ${ }^{[2]}$ However, the observed efficiency of power dissipation is much higher than the expected value ( 20 to $25 \mathrm{pct}$ ), and this may be attributed to the deformation texture-induced softening. The beta-treated zirconium and zirconium alloys were found to have "hard" texture, which may be described in terms of basal planes preferentially oriented parallel to the compression axis. The relative intensity of $\{0002\}$ reflection recorded on the surface parallel to the compression axis of an undeformed specimen has been found to be 50 pet of the $\{10 \overline{1} 1\}$ intensity, while that of $\{10 \overline{1} 0\}$ was about 20 pet. On deformation at $650^{\circ} \mathrm{C}$ and $10^{-3} \mathrm{~s}^{-1}$, the corresponding value for $\{0002\}$ reflection was 17 pet and that of $\{10 \overline{10}\}$ was 40 pct. Thus, the hard texture has changed to a "soft" texture which has at least 


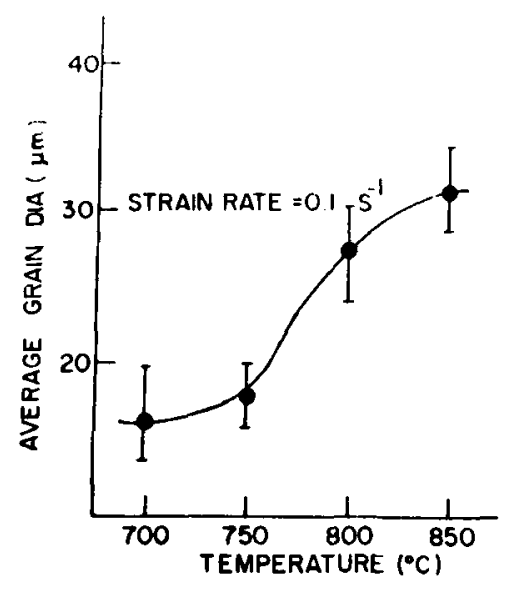

(a)

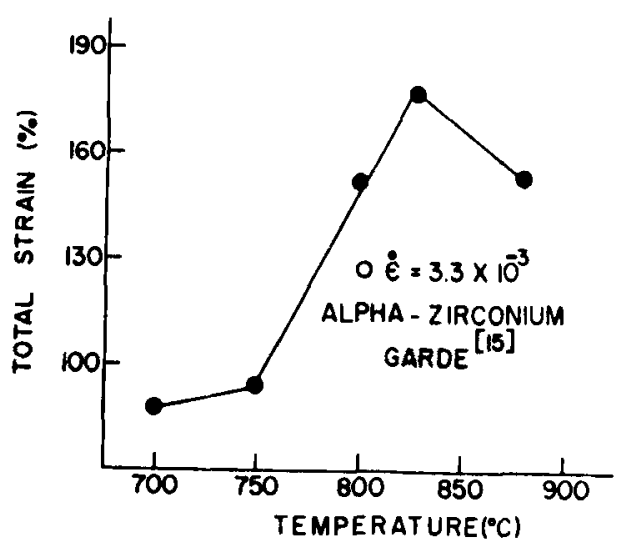

(b)

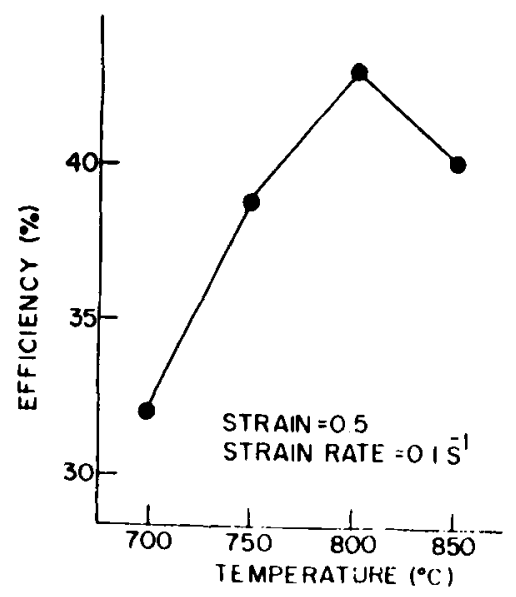

(c)

Fig. 6-Characteristics of dynamic recrystallization: (a) grain size variation with temperature at a strain rate of $0.1 \mathrm{~s}^{-1}$ and strain of 0.7 , (b) variation of total strain (in pct) with temperature, and (c) variation of efficiency of power dissipation with temperature.

twice the intensity of $\{10 \overline{1} 0\}$ planes parallel to the compression axis. The efficiency of power dissipation has also become double the expected value. Similar texture-related flow softening was also reported in zirconium and its alloys. ${ }^{[19]}$

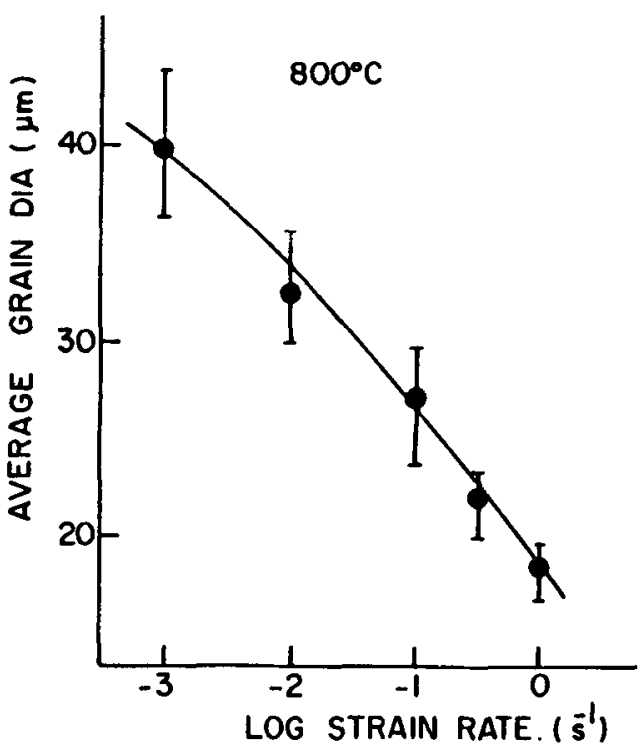

Fig. 7-Dynamically recrystallized grain size as a function of strain rate at $800^{\circ} \mathrm{C}$ for a strain of 0.7 .

\section{Microstructural Instabilities}

The continuum criterion developed by $\mathrm{Kumar}^{[10]}$ on the basis of the principle of maximum rate of entropy production described by Ziegler ${ }^{[11]}$ is used for delineating the microstructural instabilities in the processing map. $\operatorname{Kumar}^{[10]}$ has used the principle of separability in arriving at the dissipation function that relates to the metallurgical processes ( $J$ co-content) using the strain-rate sensitivity, and the variation of this dissipation function ( $J$ content) with strain rate is considered for defining the condition for the occurrence of metallurgical instability at constant temperature:

$$
\delta J / \delta \dot{\varepsilon}<J / \dot{\varepsilon}
$$

Using Eq. [3] in Eq. [7], we get the criterion for instability given $\mathrm{Eq}$. [2]. The instability revealed manifests itself in the form of localized shear bands, the typical

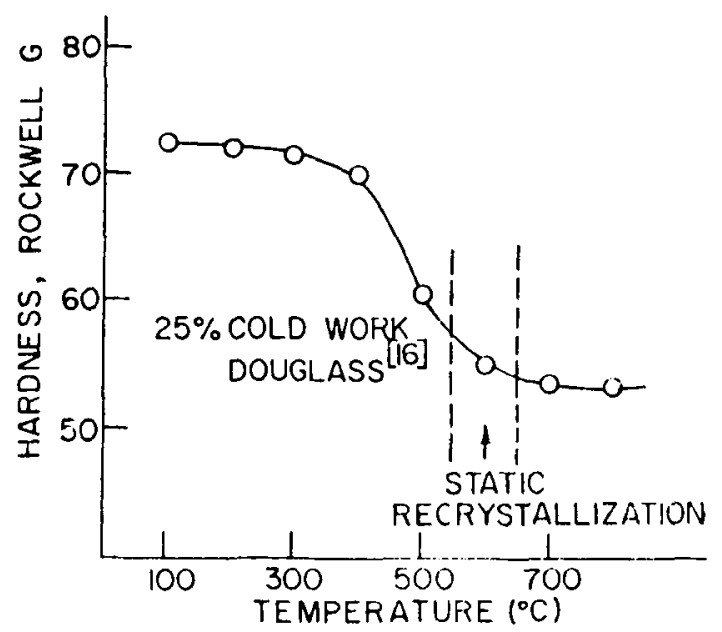

Fig. 8-Characteristic of static recrystallization of alpha-zirconiuma plot of hardness as a function of temperature, ${ }^{16]}$ 

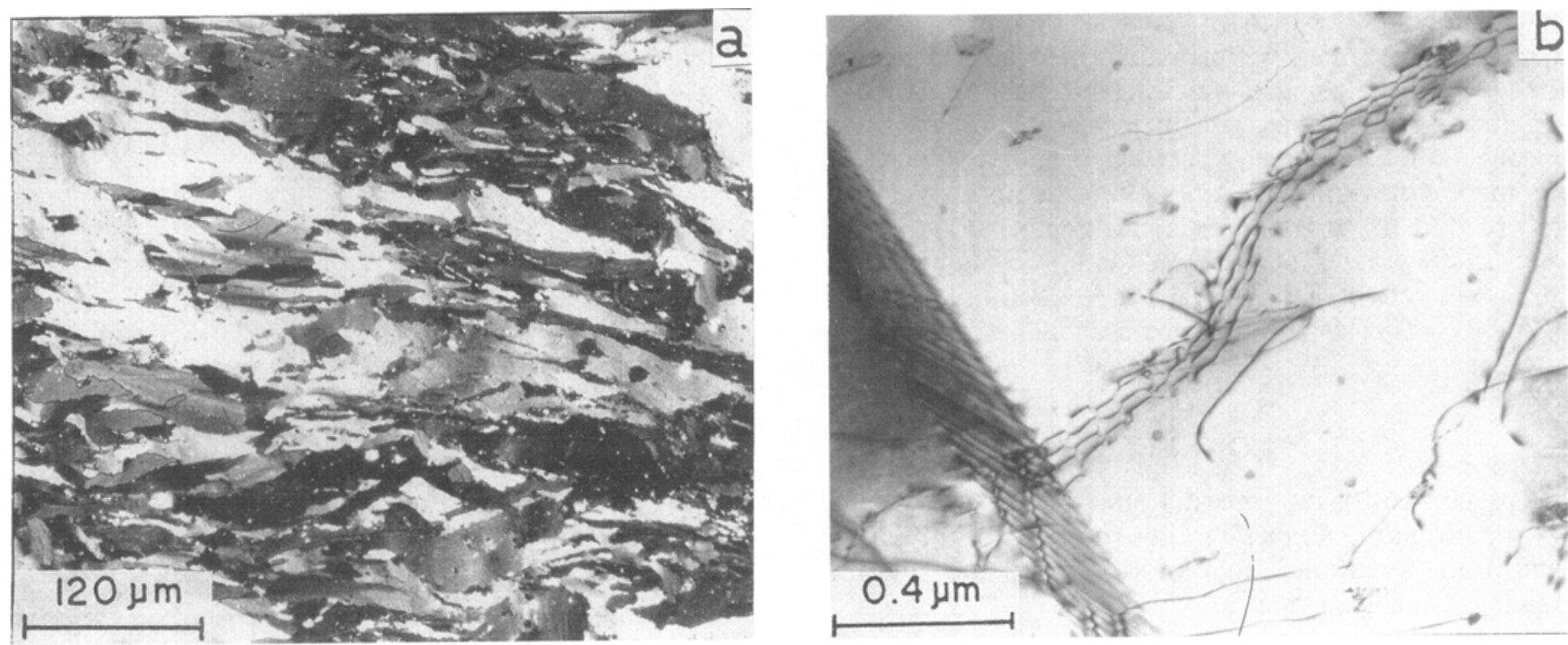

Fig. 9-Dynamically recovered structure in alpha-zirconium deformed to a strain of 0.7 at $650{ }^{\circ} \mathrm{C}$ and at a strain rate of $0.001 \mathrm{~s}^{-1}:(a)$ optical micrograph and $(b)$ transmission electron micrograph showing substructure.
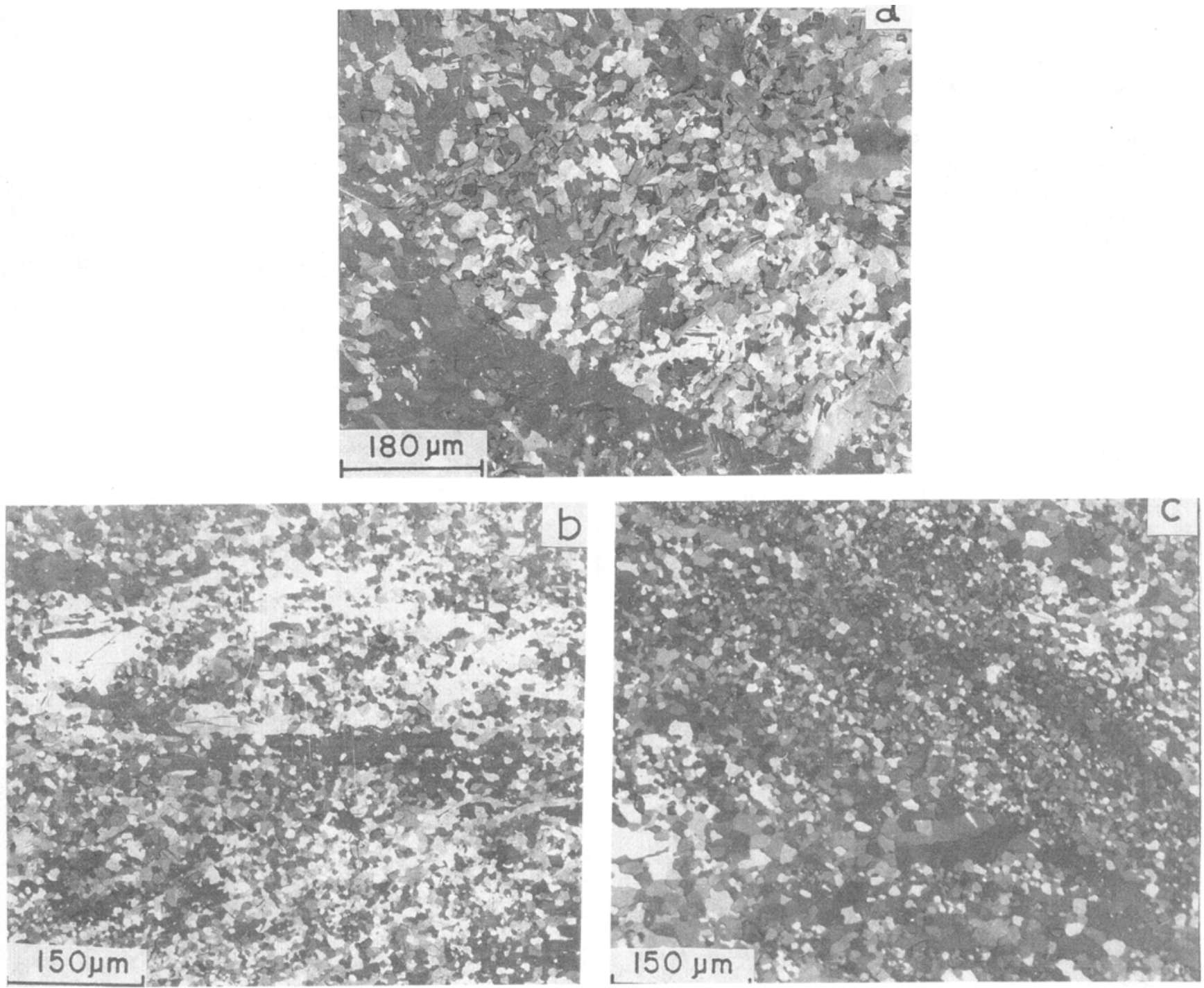

Fig. 10-Optical micrographs of the samples deformed at $700{ }^{\circ} \mathrm{C}$ showing manifestations of instability in the form of localized shear bands on deformation at (a) $10 \mathrm{~s}^{-1},(b) 1 \mathrm{~s}^{-1}$, and (c) $100 \mathrm{~s}^{-1}$. 
microstructure of which is shown in Figure 10(a). This corresponds to the specimen deformed at $700{ }^{\circ} \mathrm{C}$ and $10 \mathrm{~s}^{-1}$. It is likely that the adiabatic heating which is significant at high strain rates is responsible for this shear localization. The microstructural instability may be avoided by lowering the strain rate. The microstructures recorded on the zirconium specimen deformed at $700^{\circ} \mathrm{C}$ and at strain rates of 100,10 , and $1 \mathrm{~s}^{-1}$ confirm the strain-rate effect and validate the instability criterion (Eq. [2]). The instability domain should be avoided in processing.

\section{CONCLUSIONS}

On the basis of the processing maps obtained on alphazirconium in the temperature range of $650{ }^{\circ} \mathrm{C}$ to $850^{\circ} \mathrm{C}$ and in the strain-rate range of $10^{-3}$ to $10^{2} \mathrm{~s}^{-1}$, the following conclusions are drawn:

1. Dynamic recrystallization occurs in the temperature range of $730{ }^{\circ} \mathrm{C}$ to $850^{\circ} \mathrm{C}$ and in the strain rate range of $10^{-2}$ to $1 \mathrm{~s}^{-1}$, with its peak at $800{ }^{\circ} \mathrm{C}$ and $0.1 \mathrm{~s}^{-1}$, having efficiency of power dissipation of the order of 40 pct.

2. The characteristics of dynamic recrystallization are similar to those of static recrystallization in that sigmoidal grain size/hardness dependence is observed, although the dynamic recrystallization occurred at much higher temperatures.

3. The optimum processing parameters for hot working alpha-zirconium are $800^{\circ} \mathrm{C}$ and $0.1 \mathrm{~s}^{-1}$, at which dynamically recrystallized microstructure will result.

4. When deformed at $650{ }^{\circ} \mathrm{C}$ and $10^{-3} \mathrm{~s}^{-1}$, textureinduced dynamic recovery occurs with efficiency of power dissipation similar to dynamic recrystallization.

5. At strain rates higher than $1 \mathrm{~s}^{-1}$ and temperatures above $670{ }^{\circ} \mathrm{C}$, alpha-zirconium exhibits microstructural in- stability which manifests itself in the form of localized shear bands.

\section{REFERENCES}

1. M.J. Luton and J.J. Jonas: Can. Met. Q., 1972, vol. 11 (2), pp. $79-90$.

2. D.J. Abson and J.J. Jonas: J. Nucl. Mater, 1972, vol. 42, pp. 73-85.

3. H.J. McQueen and J.J. Jonas: Treatise On Materials Science and Technology, Academic Press, New York, NY, 1975, vol. 6, pp. 393-490.

4. D.H. Sastry, M.J. Luton, and J.J. Jonas: Phil. Mag., 1974, vol. 30 , pp. 115-27.

5. H. Buhler and H.W. Wagener: Z. Metallkd., 1967, vol. 58 (H2), pp. 136-44.

6. P. Dadras and J.F. Thomas, Jr.: Metall. Trans. A, 1981, vol. 12A, pp. 1867-73.

7. Y.V.R.K. Prasad, H.L. Gegel, S.M. Doraivelu, J.C. Malas, J.T. Morgan, K.A. Lark, and D.A. Barker: Metall. Trans. A, 1984, vol. 15A, pp. 1883-92.

8. H.L. Gegel: in Experimental Verification of Process Models, C.C. Chen, ed., ASM, Metals Park, OH, 1983, pp. 25-55.

9. Y.V.R.K. Prasad: Indian J. Technol, , 1990, vol. 28, pp. 435-51.

10. A.K.S. Kalyan Kumar: M.S. Thesis, Indian Institute of Science, Bangalore, India, Oct. 1987.

11. H. Ziegler: Progress in Solid Mechanics, John Wiley and Sons, New York, NY, 1963, vol. 4, pp. 93-113.

12. P.E. Wellstead: Introduction to Physical System Modelling, Academic Press, London, 1979.

13. I. Prigogine: Science, 1978, vol. 201, (4358), pp. 777-85.

14. R. Raj: Metall. Trans. A, 1981, vol. 12A, pp. 1089-97.

15. A.M. Garde: J. Nucl. Mater., 1979, vol. 80, pp. 195-206.

16. D.L. Douglass: Atomic Energy Review, Suppl. 1971, International Atomic Energy Agency, Vienna, Austria, 1971, pp. 129-30.

17. L.E. Murr: Interfacial Phenomena in Metal and Alloys, AddisonWesley Publishing Company, Reading, Massachusetts, 1975, pp. 1-253.

18. B.C. Allen: Trans. AIME, 1963, vol. 227, pp. 1175-83.

19. J.J. Jonas and M.J. Luton: Advances in Deformation Processing, Plenum Press, New York, NY, 1978, pp. 215-43. 